\title{
Role of diuretics, $\beta$ blockers, and statins in increasing the risk of diabetes in patients with impaired glucose tolerance: reanalysis of data from the NAVIGATOR study
}

\author{
(c) (1) (9) OPEN ACCESS
}

Lan Shen cardiology fellow ${ }^{12}$, Bimal R Shah assistant professor of medicine ${ }^{1}$, Eric M Reyes assistant professor of biostatistics and bioinformatics ${ }^{1}$, Laine Thomas assistant professor of biostatistics and bioinformatics ${ }^{1}$, Daniel Wojdyla statistician ${ }^{1}$, Peter Diem professor of medicine ${ }^{3}$, Lawrence A Leiter professor of medicine ${ }^{4}$, Bernard Charbonnel professor of medicine ${ }^{5}$, Viacheslav Mareev professor of medicine ${ }^{6}$, Edward S Horton professor of medicine ${ }^{7}$, Steven M Haffner professor of medicine ${ }^{8}$, Vladimir Soska professor of medicine ${ }^{9}$, Rury Holman professor of medicine ${ }^{10}$, M Angelyn Bethel professor of medicine ${ }^{8}$, Frank Schaper professor of medicine ${ }^{11}$, Jie-Lena Sun statistician ${ }^{1}$, John JV McMurray professor of medical cardiology ${ }^{12}$, Robert M Califf professor of medicine ${ }^{1}$, Henry Krum professor of medicine ${ }^{13}$

\footnotetext{
'Duke Clinical Research Institute, Durham, NC, USA; ${ }^{2}$ Department of Cardiology, Shanghai Renji Hospital, Shanghai Jiaotong University, China; ${ }^{3}$ Department of Endocrinology, Diabetes and Clinical Nutrition University Hospital, University of Bern, Switzerland; ${ }^{4}$ St Michael's Hospital, Toronto, Ontario, Canada; ${ }^{5}$ Endocrinology Department, University Hospital, Nantes, France; ${ }^{6}$ Lomonosov Moscow State University, Moscow, Russia; ${ }^{7} \mathrm{Joslin}$ Diabetes Center, Boston, MA, USA; ${ }^{8}$ Diabetes Trials Unit, Oxford Centre for Diabetes, Endocrinology and Metabolism, University of Oxford, Oxford, UK; ${ }^{9}$ nd Clinic of Internal Medicine and Department of Biochemistry, Faculty of Medicine, Masaryk University, Brno, Czech Republic; ${ }^{10} \mathrm{Churchill}$ Hospital, Oxford, UK; ${ }^{11}$ Center for Clinical Studies, Metabolism and Endocrinology Knowledge and Technology Transfer of Dresden University of Technology, Dresden, Germany; ${ }^{12}$ British Heart Foundation Cardiovascular Research Centre, University of Glasgow, UK; ${ }^{13}$ Monash Centre of Cardiovascular Research and Education in Therapeutics, School of Public Health and Preventive Medicine, Monash University/Alfred Hospital, Melbourne VIC 3004, Australia
}

\begin{abstract}
Objective To examine the degree to which use of $\beta$ blockers, statins, and diuretics in patients with impaired glucose tolerance and other cardiovascular risk factors is associated with new onset diabetes.

Design Reanalysis of data from the Nateglinide and Valsartan in Impaired Glucose Tolerance Outcomes Research (NAVIGATOR) trial. Setting NAVIGATOR trial.

Participants Patients who at baseline (enrolment) were treatment naïve to $\beta$ blockers $(n=5640)$, diuretics ( $n=6346)$, statins $(n=6146)$, and calcium channel blockers $(n=6294)$. Use of calcium channel blocker was used as a metabolically neutral control.
\end{abstract}

Main outcome measures Development of new onset diabetes diagnosed by standard plasma glucose level in all participants and confirmed with glucose tolerance testing within 12 weeks after the increased glucose value was recorded. The relation between each treatment and new onset diabetes was evaluated using marginal structural models for causal inference, to account for time dependent confounding in treatment assignment.

Results During the median five years of follow-up, $\beta$ blockers were started in 915 (16.2\%) patients, diuretics in 1316 (20.7\%), statins in 1353 $(22.0 \%)$, and calcium channel blockers in 1171 (18.6\%). After adjusting for baseline characteristics and time varying confounders, diuretics and statins were both associated with an increased risk of new onset diabetes (hazard ratio $1.23,95 \%$ confidence interval 1.06 to 1.44 , and $1.32,1.14$ to 1.48 , respectively), whereas $\beta$ blockers and calcium channel blockers were not associated with new onset diabetes $(1.10,0.92$ to 1.31 , and $0.95,0.79$ to 1.13 , respectively). 
Conclusions Among people with impaired glucose tolerance and other cardiovascular risk factors and with serial glucose measurements, diuretics and statins were associated with an increased risk of new onset diabetes, whereas the effect of $\beta$ blockers was non-significant.

Trial registration ClinicalTrials.gov NCT00097786.

\section{Introduction}

Use of $\beta$ blockers, diuretics, and statins has been established to reduce cardiovascular morbidity and mortality in a variety of diseases. ${ }^{1}$ However, although statins reduce cardiovascular events and mortality in patients with coronary artery disease or equivalent risk factors, ${ }^{2}$ debate continues about their role in primary prevention in lower risk populations. ${ }^{3}$

Despite the overwhelming benefits of these drugs on cardiovascular outcomes, recent evidence suggests that long term use may increase the risk of diabetes. Large trials examining cardiovascular outcomes and mortalities suggested an increased incidence of new onset diabetes with long term use of diuretics. ${ }^{45}$ Likewise, other studies have reported an increased incidence of diabetes in people treated with statins, ${ }^{3-8}$ prompting the US Food and Drug Administration to release a safety label change in $2012 .{ }^{9}$ Furthermore, $\beta$ blockers have been implicated in impaired glucose metabolism, especially with diuretics. 5

Large scale studies with serial glucose measurements examining the association between these drugs and new onset diabetes in patients with impaired glucose tolerance are limited. We reanalysed data from the Nateglinide and Valsartan in Impaired Glucose Tolerance Outcomes Research (NAVIGATOR) study to examine the relation between risk of new onset diabetes and use of $\beta$ blockers, thiazide diuretics, or statins in treatment naïve patients.

\section{Methods}

NAVIGATOR was a multinational, randomised, double blinded, placebo controlled trial examining the effects of valsartan and nateglinide on conversion to type 2 diabetes mellitus and cardiovascular outcomes in patients with impaired glucose tolerance and other cardiovascular risk factors. The study design and results have been previously published, ${ }^{10-12}$ as have the eligibility criteria (see supplementary appendix). ${ }^{12}$

\section{Endpoint definitions}

The endpoint of interest was diagnosis of new onset diabetes. We measured fasting plasma glucose every six months for the first three years of follow-up and then annually. Oral glucose tolerance tests were performed yearly. New onset diabetes was defined by a fasting plasma glucose level $\geq 126 \mathrm{mg} / \mathrm{dL}$ ( 7.0 $\mathrm{mmol} / \mathrm{L})$ or a glucose level $\geq 200 \mathrm{mg} / \mathrm{dL}(11.1 \mathrm{mmol} / \mathrm{L})$ two hours after an oral glucose tolerance test, confirmed by an oral glucose tolerance test within 12 weeks after the increased glucose value was recorded. We separated the diabetes endpoint into 12 time windows (every six months for three years and 12 months subsequently).

\section{Drugs}

We studied calcium channel blockers as a potential metabolically "neutral" control and expected that their use would be similar to that of $\beta$ blockers, diuretics, and statins and, therefore, would have a similar potential for unmeasured confounding. However, calcium channel blocker use should not have any adverse or beneficial metabolic impact. ${ }^{13}$ As a negative control, to evaluate our methodology, we also assessed the relation between receiving a calcium channel blocker and subsequent progression to new onset diabetes. $\beta$ blockers, diuretics, statins, and calcium channel blockers were prescribed to patients in the

NAVIGATOR trial as part of routine clinical care, and recorded subsequent to randomisation.

\section{Study population}

Although many patients were taking cardiovascular therapies at baseline, this cohort represents a heterogeneous group with unknown, differential lengths of exposure to treatment and unknown circumstances preceding treatment initiation. In addition, patients who developed diabetes, potentially as a consequence of these drugs, would not be eligible for the study, leaving a biased sample of patients taking drugs at baseline. To avoid these biases, we evaluated treatment initiation in a population that was treatment naïve to each class of drug at baseline. Thus, of 9306 patients enrolled in NAVIGATOR, four unique subgroups were identified for evaluating each therapy (figure $\Downarrow)$ : $\beta$ blockers $(n=5640)$, diuretics $(n=6346)$, statins $(n=6146)$, and calcium channel blockers $(n=6294)$. In this study, the median follow-up time for diabetes was five years from baseline, with a maximum of six years.

\section{Covariate follow-up}

We identified potential confounders in the relation between non-randomised treatments and progression to new onset diabetes through known clinical risk factors, with additional input obtained from consensus of the clinical and analytical team. The reasons for initiating each therapy and variables known to be highly associated with new onset diabetes were listed and we mapped these to the corresponding variable in the NAVIGATOR trial (table $1 \Downarrow$ ). Given that the population was treatment naïve at baseline, post-baseline information on these covariates was possibly informative. Updated values for time dependent confounders were available according to the visit schedule in table 1.

\section{Statistical analysis}

Among the treatment naïve populations, we compared baseline characteristics between those who did and did not receive treatment. We summarised continuous characteristics using the median (25th, 75th centile) and compared them using the Student's $t$ test; categorical variables were summarised with frequency and percentage and compared using the Pearson $\chi^{2}$ or Fisher exact test.

To evaluate the effect of the drugs on progression to diabetes, we constructed four marginal structural models,,${ }^{14}$ one for each drug. Unlike traditional methods, this approach can account for treatment selection bias that may depend on baseline and time dependent variables. ${ }^{15}$ The marginal structural model closely resembles a Cox model, with baseline covariate adjustment and treatment included as a time dependent covariate. Specifically, the treatment of interest was assigned the value 0 during periods in which treatment was withheld and 1 when treatment was used, potentially reflecting starting, stopping, and subsequent changes. The distinguishing feature of the marginal structural model is that inverse probability of treatment weighting is applied to account for time dependent variables that may be associated with initiating or discontinuing treatment. The propensity to receive treatment is recalculated according to new information at each time interval, and the weights are correspondingly updated. Under the assumption of no unmeasured confounders, baseline or time varying, the observed treatment patterns become pseudorandomised. The resemblance 
to the Cox model allows estimation of a hazard ratio, with the usual proportional hazards interpretation. We used the Breslow method to handle tied events times (because diabetes was measured only at six or 12 month intervals), which facilitated the use of weights. We censored the follow-up for diabetes at six years, beyond which the data were too sparse to adequately adjust for confounding.

In the model we included as covariates those baseline variables that were previously identified as significantly associated with new onset diabetes in the NAVIGATOR trial. We modelled the propensity to receive treatment at each time window as a function of all time dependent covariates listed in table 1 , updated to their value at the previous time window. The rationale was that these treatments are often used in conjunction and that known reasons for initiation of one treatment may be associated with the use of other treatments, regardless of a direct impact. Moreover, we adjusted for time dependent measures of fasting glucose and oral glucose tolerance. This adjustment allowed us to balance patients according to precursor measurements of the endpoint itself. To account for selective loss to follow-up, we similarly modelled the propensity to be censored. At each time point, we calculated stabilised weights using inverse probability of treatment and inverse probability of censoring. ${ }^{14} \mathrm{We}$ fit all continuous variables using a flexible spline to account for possible non-linearity. Approximately $20 \%$ of patients were missing a variable of interest at baseline (primarily glycated haemoglobin, $\mathrm{HbA}_{1 \mathrm{c}}$ ). Baseline missing data were multiply imputed, and final estimates (and associated standard errors) reflect the combined analysis over five imputed datasets. We measured time dependent variables with varying frequency and additionally exhibited missing data. For time dependent variables we used a last value carried forward approach, within each imputation. We think this is reasonable as it captures the most recent available information for decision making. The measurement schedule is included in the supplementary file.

As with inverse probability of treatment weighting, it is important to assess and minimise the impact of extreme weights, by which a few patients who are unlikely to receive treatment could exert undue influence on the results. Previous investigators recommend conducting a series of sensitivity analyses, successively truncating the weights to evaluate variation in the results. ${ }^{16}$ Extreme weights were rare within the six year follow-up period. We report the primary results based on minimal truncation of weights at the 0.25 and 99.75 centiles.

Alternative truncation strategies did not change the results and are reported in the supplementary file.

As with a time dependent Cox model, the primary result of the marginal structural model is a hazard ratio for treatment. To improve clinical interpretability, we sought to illustrate the discrepancy in event rates implied by the observed hazard. We used the marginal structural model to derive adjusted, five year event probabilities for two hypothetical trajectories of the time dependent covariate: no treatment throughout follow-up, or constant treatment throughout follow-up. Specifically, we used the Breslow estimator (1 minus the exponential of the negative empirical cumulative hazard estimate), fixing the level of treatment ( 0 and 1$)$ and balancing other covariates by weighting (that is, fitting the marginal structural model). This estimation corresponds to the standard calculations for a Cox model, with the addition of weights. The absolute excess risk at five years was calculated as the difference between five year event probabilities, and its inverse was the number needed to harm. Confidence intervals for number needed to harm were calculated according to the Altman method. ${ }^{17}$
As a point of comparison, we also fit the standard Cox proportional hazard model including the treatment of interest as a time dependent covariate, initially unadjusted and then adjusted only for baseline characteristics. This model cannot account for the changes in patients' characteristics that led to treatment decisions and therefore is likely to be biased.

\section{Results}

Among the 9306 participants enrolled in the NAVIGATOR trial, 915 (16.2\%) of 5640 who were $\beta$ blocker naïve at baseline started $\beta$ blocker treatment during follow-up, 1316 (20.7\%) of 6346 who were diuretic naïve started diuretic treatment, 1353 $(22.0 \%)$ of 6146 who were statin naïve started statin treatment, and $1171(18.6 \%)$ of 6294 who were calcium channel blocker naïve started calcium channel blocker treatment. In treatment naïve patients, those who started treatment had baseline fasting blood glucose and $\mathrm{HbA}_{1 \mathrm{c}}$ levels similar to those in patients who never started on any of the four therapies. Compared with patients who did not start treatment, patients who did start any of the four therapies were older and more likely to have hypertension, congestive heart failure, a history of coronary artery bypass graft surgery, angina, or other major cardiovascular events. Among the four treatment naïve groups, baseline values for blood pressure, weight, sex, and albumin/creatinine ratios were similar to those in patients who started therapy (table $2 \Downarrow$ ).

Frequency of concomitant drug use was similar across the therapies of interest. For example, statins were used in $40 \%$, $39 \%$, and $40 \%$ among patients taking $\beta$ blockers, diuretics, and calcium channel blockers at one year, respectively. The results were similar for other pairings, and across time (see supplementary file for details).

\section{Incidence of new onset diabetes}

After adjusting for baseline characteristics and time varying covariates, patients receiving diuretics and statins had significantly higher rates of new onset diabetes compared with patients not starting treatment (table $3 \Downarrow$ ). The marginal structural model adjusted hazard ratio for new onset diabetes in patients treated with diuretics compared with those who were not was 1.23 (95\% confidence interval 1.06 to 1.44 ); the number needed to harm was 17 (95\% confidence interval 9 to 68). Likewise, the marginal structural model hazard ratio for new onset diabetes in the statin treated group, compared with the non-treated group, was 1.32 (1.14 to 1.48); the number needed to harm was 12 ( 8 to 29 ). For the $\beta$ blockers group, the risk of new onset diabetes was numerically higher but non-significant (marginal structural model hazard ratio $1.10,0.92$ to 1.31 ). No association was found between calcium channel blocker use and development of new onset diabetes (marginal structural model hazard ratio 0.95, 0.79 to 1.13). The results remained stable in sensitivity analyses involving different truncations of weights. Table 3 displays the results from unadjusted and baseline adjusted Cox proportional hazard models.

\section{Discussion}

After adjustment for baseline and time varying confounders, diuretic use and statin use were significantly associated with new onset diabetes. For $\beta$ blockers, a non-significant difference in the development of new onset diabetes was observed. Our findings provide further evidence that in high risk people with impaired glucose tolerance, use of diuretics and statins may be associated with an increased risk of new onset diabetes. 
Before studying the effect of each drug on development of new onset diabetes, we first examined the concomitant use of those drugs in the NAVIGATOR (Nateglinide and Valsartan in Impaired Glucose Tolerance Outcomes Research) trial. We found that in this high risk population, as expected, statins were used as a concomitant therapy with $\beta$ blockers as often as with diuretics and calcium channel blockers. Although we did not analyse drug-drug and drug-disease interactions, by accounting for concomitant treatment usage, we limited the confounding of multiple drugs on new onset diabetes. Given this methodology, our study further supports the independent effect of statins on new onset diabetes and emphasises the substantial net effect in a high risk population with impaired glucose tolerance.

In the past decade, studies have found varying associations between diabetes risk and use of $\beta$ blockers, diuretics, and statins. ${ }^{18}{ }^{19}$ Compared with previous studies using investigator reported or patient reported data on new onset diabetes or administrative claims, the NAVIGATOR trial used serial glucose measurements that enhanced detection of risk for new onset diabetes in a high risk population with impaired glucose tolerance. We found that the increased risk of new onset diabetes associated with diuretic use was similar to that of previous studies. ${ }^{20}$ Some observational studies have shown a $20 \%$ to $40 \%$ increased risk of developing new onset diabetes in patients taking compared with not taking diuretics, ${ }^{1321}$ whereas other studies have shown similar risks of development for new onset diabetes in patients treated with diuretics compared with angiotensin converting enzyme inhibitors. ${ }^{22}$

In several major antihypertensive studies, among non-diabetic patients with hypertension, the number needed to harm with respect to new onset diabetes ranged from 125 to 167 over four to six years of follow-up. ${ }^{8}$ In The Antihypertensive and Lipid-Lowering Treatment to Prevent Heart Attack Trial, among patients with hypertension and a high risk of cardiovascular disease, the incidence of diabetes at four years was $11.6 \%$ for chlorthalidone and $9.8 \%$ for amlodipine (number needed to harm for chlorthalidone $=167$ at four years of follow-up) ${ }^{20}$ For the Captopril Prevention Project study among hypertensive, non-diabetic patients, the number needed to harm for diuretic or $\beta$ blocker therapy, or both was 125 at six years of follow-up. ${ }^{23}$ However, the effect of diuretics had not yet been examined in an impaired glucose tolerance population. In our study, one additional case of diabetes occurred within five years for every 17 patients treated with diuretics. This lower number needed to harm can be attributed to our population of patients with impaired glucose tolerance having a high propensity for new onset diabetes and serial glucose measurement.

Among patients taking $\beta$ blockers, previous studies have reported up to a sixfold increased risk of new onset diabetes. ${ }^{24}$ In the Losartan Intervention For Endpoint reduction in hypertension study, among non-diabetic hypertensive patients with left ventricular hypertrophy, the incidence of diabetes was $6 \%$ compared with $8 \%$ for patients taking losartan versus atenolol (adjusted hazard ratio $0.75,95 \%$ confidence interval 0.63 to 0.88$).{ }^{25}$ In another large prospective trial with new onset diabetes as a primary endpoint among non-diabetic hypertensive patients, those taking $\beta$ blockers compared with not taking $\beta$ blockers had a $28 \%$ increased risk of developing subsequent diabetes (adjusted hazard ratio 1.28, 95\% confidence interval 1.04 to 1.57$){ }^{26}$ The mechanism of $\beta$ blocker induced new onset diabetes has been postulated to result from a combination of changes in lipoprotein lipase activity, attenuation of the release of insulin by pancreatic $\beta$ cells, weight gain where increased adiposity constrains the distribution of insulin, and peripheral vasoconstriction from unopposed $\alpha$ adrenergic activity. ${ }^{5}$ In our analysis, we did not find a statistically significant association between use of $\beta$ blockers and new onset diabetes. However, the estimated hazard ratio of 1.10 and confidence interval $(0.92$ to 1.31) were not inconsistent with previous studies. Thus, an important detrimental effect cannot be excluded, and a large sample size would be required to detect a moderate effect. Furthermore, the lack of significant association may also be attributed to the mixed receptor specificity, dosage, and duration of $\beta$ blocker treatment in our study, as other studies of $\beta$ blockers have yielded varying results based on the categories and dosages used. $^{27}$

Initial data linking statin use and diabetes suggested a protective effect of these drugs. The West of Scotland Coronary Prevention Study reported a $30 \%$ reduction in the hazard of developing diabetes with pravastatin. ${ }^{28}$ However, more recent studies examining higher potency statins have suggested a link between statin potency and risk of new onset diabetes. One study reported that statin use resulted in a $48 \%$ increased risk of new onset diabetes in postmenopausal women. ${ }^{29}$ Likewise, results from the Justification for the Use of Statins in Prevention: an Intervention Trial Evaluating Rosuvastatin (JUPITER) showed a $25 \%$ higher proportion in investigator reported diabetes in patients treated with rosuvastatin versus placebo. ${ }^{3} \mathrm{~A}$ meta-analysis of 13 trials involving 91140 patients showed a $9 \%$ increased risk of diabetes among statin treated patients, leading the Food and Drug Administration in 2012 to add a warning label to statin drugs marketed and sold in the United States. ${ }^{9}$ The relative effect of statins on new onset diabetes was similar in our study, with a $32 \%$ increased risk of new onset diabetes in patients receiving statins. Compared with previous studies, our population with impaired glucose tolerance has a smaller number needed to harm, with one case of new onset diabetes for every 12 patients treated over five years; whereas in a population with non-impaired glucose tolerance, the number needed to harm has been as high as 255 over four years. ${ }^{7}$ Although the relative risk was similar, we saw a greater net impact of statin therapy on new onset diabetes than in previous studies, in our population of high risk patients with impaired glucose tolerance.

Another study of patients at high risk of new onset diabetes included a subgroup of patients from the JUPITER trial, which examined patients with major risk factors for diabetes, including metabolic syndrome, impaired fasting glucose, and high body mass index or $\mathrm{HbA}_{\mathrm{lc}}$ levels, and showed a hazard ratio for statin therapy similar to that in our study $(1.28,95 \%$ confidence interval 1.07 to 1.54$).{ }^{8}$ However, this study had a lower event rate than in our study (treated versus untreated, $2.12 \% v 1.65 \%$, and $41 \% v 33 \%$, respectively) over a similar follow-up period. Therefore, we found a much higher net risk towards new onset diabetes compared with other high risk populations with diabetes. Again, this difference may be due to the patients with impaired glucose tolerance in our study being closer to the threshold for overt new onset diabetes than the patients with metabolic syndrome from JUPITER, as well as the use of serial glucose measurements with laboratory confirmation, allowing for a more accurate and thus higher detection rate of diabetes.

The potential for unmeasured confounding remains a concern in this observational study. To the extent that these treatments are used in similar populations, the magnitude of unmeasured bias may be reflected in the hazard ratio estimate for calcium channel blockers. Other hazard ratios can be compared with calcium channel blockers (hazard ratio 0.95 ) rather than to a hazard ratio of 1 . We observed that the confidence intervals for statins and diuretics did not contain 0.95 , strengthening the case 
against them. The confidence interval for $\beta$ blockers did contain 0.95 and is therefore not convincingly different from our metabolically neutral control.

The marginal results for the structural model are consistent with a reduction in treatment selection bias, whereby higher risk patients are more likely to receive treatment. The hazard ratios from the unadjusted and baseline adjusted Cox models are generally higher than those from the marginal structural model. Interestingly, the baseline adjusted Cox model provides nearly identical results to that of the unadjusted model. This likely reflects the fact that the population was treatment naïve at baseline and post-baseline factors play a role in post-baseline treatment use. This emphasises the important role of adjustment for post-baseline factors.

\section{Strengths and limitations of this study}

Our study has three major strengths compared with previous studies. Firstly, our study is large; the largest of its kind to date. Secondly, our study used standard methods for diagnosing diabetes, with prespecified serial glucose assessments and laboratory confirmation for all patients, whereas other studies have relied on billing data ${ }^{8}$ or pooled results data in meta-analyses. ${ }^{67}$ Thirdly, we began with a treatment naïve population and used marginal structural models to account for the time varying confounders for the use of drug therapy and its association with new onset diabetes. This allowed pseudorandomisation of treatment strategies in which, at each visit, patients who had not yet progressed to diabetes were re-examined for use of the drugs of interest according to their full covariate history. By only including a treatment naïve population, we estimated the effect of first time initiation of drugs on new onset diabetes.

Firstly, this was a reanalysis of a clinical trial that was not prospectively designed to examine the association between new onset diabetes and $\beta$ blocker, statin, and diuretic use. Biases due to the observational nature of treatment assignment are possible. Documentation of the reason for initiation of new non-trial study treatment was not collected as part of the trial protocol. Although the NAVIGATOR dataset captured strong predictors of new onset diabetes and all known factors expected to be associated with treatment use, these measured confounders were not measured perfectly. For example, glucose tolerance and blood pressure are known to be measured with error, which could lead to imperfect adjustment. The interval nature of data collection implied that covariates could only be updated to their most recent value, six months before treatment decisions, but not immediately before. Given the potential for residual treatment selection bias, we emphasised the comparison with calcium channel blocker. Secondly, we were unable to examine the effects of treatment stratified by duration of drug use- that is, we did not explore differential effects according to the duration of use but estimated the effect averaged over duration. Because we did not collect information on dosage or category, we cannot determine whether there was a dose or category response for these drugs, especially when previous studies have showed that diuretic and $\beta$ blocker effect can vary within these classes of drugs, and intensive dose (versus lower dose) statins may be associated with an increased risk of new onset diabetes. ${ }^{7}$ Thirdly, we fit proportional hazards models and did not attempt to investigate time varying effects of treatment, as a more complex model would have trade-offs in precision and interpretability. Finally, we did not examine the effect of new onset diabetes on cardiovascular disease outcomes, so we cannot determine the effect of increased rate of diabetes on major outcomes in this population at high risk for cardiovascular disease.

\section{Conclusions}

We found that in high risk patients with impaired glucose tolerance and established cardiac risk factors, statins and diuretics increased the risk of new onset diabetes. Our findings suggest that glycaemia should be better monitored when these drugs are initiated in high risk patients. However, these findings should be confirmed in subsequent studies where those agents are prospectively prescribed in a randomised manner among patients at high risk of diabetes.

We thank Morgan deBlecourt, a full- time employee of the Duke Clinical Research Institute, for editorial assistance.

Contributors: LS was the first author of the literature search and contributed to the figure creation, study design, data analysis, data interpretation, and writing. BRS contributed significantly to the writing of the final manuscript, statistical methodology, and data interpretation. EMR performed the data analysis. LT contributed to the study design, data analysis and interpretation, and writing. PD contributed to the study design, manuscript drafting, and final approval of the manuscript. LAL contributed to the data review and interpretation and manuscript review. $\mathrm{BC}$ contributed to the data interpretation and manuscript review. VM helped perform the literature search and contributed to the study design, data collection, and data interpretation. ESH contributed to the study design, data interpretation, and manuscript review and revision. SMH contributed to the trial design and manuscript review. VS contributed to data acquisition, interpretation of results, and manuscript drafting. $\mathrm{RH}$ contributed to the data collection, manuscript revision, and final manuscript approval. MAB contributed to the study design, data collection, and data interpretation. FS contributed to the study design, data analysis, and data interpretation. JS contributed to the data analysis. JJVM contributed to the study design and manuscript review. $\mathrm{RMC}$ contributed to the primary study design, data interpretation, and manuscript review/revision. HK (guarantor) contributed to the writing, data analysis, and data interpretation.

Funding: NAVIGATOR was sponsored by Novartis Pharma.

Role of the funding source: The NAVIGATOR study was designed by Novartis Pharma in collaboration with an academic executive committee. All statistical analyses relevant to this publication were performed independently by statisticians at the Duke Clinical Research Institute (Durham, NC). The authors of this manuscript are solely responsible for the design and conduct of this study, all statistical analyses, and the drafting and editing of the paper and its final contents.

Competing interests: All authors have completed the ICMJE uniform disclosure form at www.icmje.org/coi_disclosure.pdf and declare: BRS served as a consultant for Cardinal Health and Castlight Health. PD received consulting fees, honoraria and research support from Novartis. $L A L$ received honorariums or research support from Amgen, AstraZeneca, Boehringer Ingelheim, Bristol-Myers Squibb, Eli Lilly, GlaxoSmithKline, Janssen, Merck, Novartis, Novo Nordisk, Sanofi, Servier, and Takeda. BC received fees for consultancy, speaking, travel, or accommodation from AstraZeneca, Bristol-Myers Squibb, Boehringer Ingelheim, GlaxoSmithKline, Janssen, Eli Lilly, Merck-Sharp \& Dohme, Novartis, Novo Nordisk, Roche, Sanofi-Aventis, and Takeda. ESH received honorariums from Novartis for service on committees and advisory boards, including the design and conduct of the NAVIGATOR trial and the NAVIGATOR trial publications committee. SMH served on the executive committee for the NAVIGATOR trial (received honorariums from Novartis). $\mathrm{RH}$ received research funding from Novartis. MAB received research support from Novartis and Bayer. Her department has received research funding from Merck, Amylin, Eli Lilly, and Bristol-Myers Squibb. All disclosures for RMC are available at www.dcri. 


\section{What is already known on this topic}

$\beta$ blockers and diuretics may increase the risk of new onset diabetes

Recent evidence suggests that statins also increase this risk

The degree to which use of these drugs in patients with impaired glucose tolerance and other cardiovascular risk factors is associated with new onset diabetes is unknown

\section{What this study adds}

Among people with impaired glucose tolerance and other cardiovascular risk factors and with serial glucose measurements, diuretics and statins were associated with an increased risk of new onset diabetes

The effect of $\beta$ blockers was, however, indeterminate

org/about-us/conflict-of-interest/Califf-COI_2012.pdf. HK was a member of the NAVIGATOR Steering Committee.

Ethical approval: The NAVIGATOR trial was approved by each centre's ethics committee. All patients provided written informed consent.

Data sharing: No additional data available.

Transparency: The lead author affirms that this manuscript is an honest, accurate, and transparent account of the study being reported; that no important aspects of the study have been omitted; and that any discrepancies from the study as planned have been explained.

1 Chobanian AV, Bakris GL, Black HR, Cushman WC, Green LA, Izzo JL Jr, et al. The Seventh Report of the Joint National Committee on Prevention, Detection, Evaluation, and Treatment of High Blood Pressure: the JNC 7 report. JAMA 2003-289-2560-72.

2 Randomised trial of cholesterol lowering in 4444 patients with coronary heart disease: the Scandinavian Simvastatin Survival Study (4S). Lancet 1994;344:1383-9.

3 Ridker PM, Danielson E, Fonseca FA, Genest J, Gotto AM Jr, Kastelein JJ, et al. Rosuvastatin to prevent vascular events in men and women with elevated $\mathrm{C}$-reactive protein. N Engl J Med 2008;359:2195-207.

4 Major cardiovascular events in hypertensive patients randomized to doxazosin vs chlorthalidone: the antihypertensive and lipid-lowering treatment to prevent heart attack trial (ALLHAT). ALLHAT Collaborative Research Group. JAMA 2000;283:1967-75.

5 Dahlof B, Sever PS, Poulter NR, Wedel H, Beevers DG, Caulfield M, et al. Prevention of cardiovascular events with an antihypertensive regimen of amlodipine adding perindopril as required versus atenolol adding bendroflumethiazide as required, in the Anglo-Scandinavian Cardiac Outcomes Trial-Blood Pressure Lowering Arm (ASCOT-BPLA): a multicentre randomised controlled trial. Lancet 2005;366:895-906.

6 Rajpathak SN, Kumbhani DJ, Crandall J, Barzilai N, Alderman M, Ridker PM. Statin therapy and risk of developing type 2 diabetes: a meta-analysis. Diabetes Care 2009;32:1924-9.

7 Sattar N, Preiss D, Murray HM, Welsh P, Buckley BM, de Craen AJ, et al. Statins and risk of incident diabetes: a collaborative meta-analysis of randomised statin trials. Lancet 2010:375:735-42.

8 Ridker PM, Pradhan A, MacFadyen JG, Libby P, Glynn RJ. Cardiovascular benefits and diabetes risks of statin therapy in primary prevention: an analysis from the JUPITER trial. Lancet 2012;380:565-71.

9 FDA Drug Safety Communication: important safety label changes to cholesterol-lowering statin drugs. 2013. www.fda.gov/Drugs/DrugSafety/ucm293101.htm.

10 Holman RR, Haffner SM, McMurray JJ, Bethel MA, Holzhauer B, Hua TA, et al. Effect of nateglinide on the incidence of diabetes and cardiovascular events. N Engl J Med 2010;362:1463-76

11 NAVIGATOR Study Group; McMurray JJ, Holman RR, Haffner SM, Bethel MA, Holzhaue $B$, Hua TA, et al. Effect of valsartan on the incidence of diabetes and cardiovascular events. N Engl J Med 2010;362:1477-90.

12 Krum H, McMurray JJ, Horton E, Gerlock T, Holzhauer B, Zuurman L, et al. Baseline characteristics of the Nateglinide and Valsartan Impaired Glucose Tolerance Outcomes Research (NAVIGATOR) trial population: comparison with other diabetes prevention trials. Cardiovasc Ther 2010;28:124-32.

13 Taylor EN, Hu FB, Curhan GC. Antihypertensive medications and the risk of incident type 2 diabetes. Diabetes Care 2006:29:1065-70.

14 Robins JM, Hernan MA, Brumback B. Marginal structural models and causal inference in epidemiology. Epidemiology 2000;11:550-60.

15 Neugebauer R, Fireman B, Roy JA, O'Connor PJ, Selby JV. Dynamic marginal structural modeling to evaluate the comparative effectiveness of more or less aggressive treatment intensification strategies in adults with type 2 diabetes. Pharmacoepidemiol Drug Saf 2012;21(Suppl 2):99-113

16 Hernan MA, Robins JM. Method for conducting sensitivity analysis. Biometrics 1999;55:1316-7.

17 Stolk RP, van Splunder IP, Schouten JS, Witteman JC, Hofman A, Grobbee DE. High blood pressure and the incidence of non-insulin dependent diabetes mellitus: findings in a 11.5 year follow-up study in The Netherlands. Eur J Epidemiol 1993;9:134-9.

18 Gurwitz JH, Bohn RL, Glynn RJ, Monane M, Mogun H, Avorn J. Antihypertensive drug therapy and the initiation of treatment for diabetes mellitus. Ann Intern Med 1993;118:273-8.

19 Skarfors ET, Lithell HO, Selinus I, Aberg H. Do antihypertensive drugs precipitate diabetes in predisposed men? BMJ 1989;298:1147-52.

20 Barzilay JI, Davis BR, Cutler JA, Pressel SL, Whelton PK, Basile J, et al. Fasting glucose levels and incident diabetes mellitus in older nondiabetic adults randomized to receive 3 different classes of antihypertensive treatment: a report from the Antihypertensive and Lipid-Lowering Treatment to Prevent Heart Attack Trial (ALLHAT). Arch Intern Med 2006;166:2191-201

21 Carter BL, Einhorn PT, Brands M, He J, Cutler JA, Whelton PK, et al. Thiazide-induced dysglycemia: call for research from a working group from the national heart, lung, and blood institute. Hypertension 2008:52:30-6.

22 Hansson L, Lindholm LH, Ekbom T, Dahlöf B, Lanke J, Scherstén B, et al. Randomised trial of old and new antihypertensive drugs in elderly patients: cardiovascular mortality and morbidity the Swedish Trial in Old Patients with Hypertension-2 study. Lancet 1999;354:1751-6.

23 Hansson L, Lindholm LH, Niskanen L, Lanke J, Hedner T, Niklason A, et al. Effect of angiotensin-converting-enzyme inhibition compared with conventional therapy on cardiovascular morbidity and mortality in hypertension: the captopril prevention project (CAPPP) randomised trial. Lancet 1999;353:611-6.

24 Samuelsson O, Hedner T, Berglund G, Persson B, Andersson OK, Wilhelmsen L. Diabetes mellitus in treated hypertension: incidence, predictive factors and the impact of non-selective beta-blockers and thiazide diuretics during 15 years treatment of middle-aged hypertensive men in the Primary Prevention Trial Göteborg, Sweden. J Hum Hypertens 1994;8:257-63.

25 Dahlof B, Devereux RB, Kjeldsen SE, Julius S, Beevers G, de Faire U, et al. Cardiovascular morbidity and mortality in the Losartan Intervention For Endpoint reduction in hypertension study (LIFE): a randomised trial against atenolol. Lancet 2002;359:995-1003.

26 Gress TW, Nieto FJ, Shahar E, Wofford MR, Brancati FL. Hypertension and antihypertensive therapy as risk factors for type 2 diabetes mellitus. Atherosclerosis Risk in Communities Study. N Engl J Med 2000;342:905-12.

27 Adverse reactions to bendrofluazide and propranolol for the treatment of mild hypertension Report of Medical Research Council Working Party on Mild to Moderate Hypertension. Lancet 1981;2:539-43.

28 Freeman DJ, Norrie J, Sattar N, Neely RD, Cobbe SM, Ford I, et al. Pravastatin and the development of diabetes mellitus: evidence for a protective treatment effect in the West of Scotland Coronary Prevention Study. Circulation 2001:103:357-62.

29 Culver AL, Ockene IS, Balasubramanian R, Olendzki BC, Sepavich DM, Wactawski-Wende $\mathrm{J}$, et al. Statin use and risk of diabetes mellitus in postmenopausal women in the Women's Health Initiative. Arch Intern Med 2012;172:144-52.

Accepted: 30 October 2013

\section{Cite this as: BMJ 2013:347:f6745}

This is an Open Access article distributed in accordance with the Creative Commons Attribution Non Commercial (CC BY-NC 3.0) license, which permits others to distribute, remix, adapt, build upon this work non-commercially, and license their derivative works on different terms, provided the original work is properly cited and the use is non-commercial. See: http://creativecommons.org/licenses/by-nc/3.0/. 


\section{Tables}

\section{Table 1 | Follow-up of time dependent confounders}

\begin{tabular}{|c|c|c|}
\hline Variables & Treatment $^{*}$ & Frequency of measurement \\
\hline \multicolumn{3}{|l|}{ Vital signs: } \\
\hline Systolic blood pressure & $\begin{array}{l}\text { Calcium channel blockers, } \beta \text { blockers, } \\
\text { diuretics }\end{array}$ & \multirow[t]{5}{*}{ Every 6 months } \\
\hline Diastolic blood pressure & $\begin{array}{l}\text { Calcium channel blockers, } \beta \text { blockers, } \\
\text { diuretics }\end{array}$ & \\
\hline Heart rate & $\beta$ blockers & \\
\hline Smoking status & Statins & \\
\hline Body mass index & Statins & \\
\hline \multicolumn{3}{|l|}{ Covarying events: } \\
\hline $\begin{array}{l}\text { Cardiovascular endpoint: myocardial infarction, coronary } \\
\text { revascularisation, and hospital admission for unstable angina }\end{array}$ & Statins, $\beta$ blockers & \multirow[t]{5}{*}{ Every 6 months } \\
\hline Atrial fibrillation & $\beta$ blockers & \\
\hline Congestive heart failure & Diuretics, $\beta$ blockers & \\
\hline Peripheral revascularisation & Statins & \\
\hline $\begin{array}{l}\text { Cerebrovascular disease: composite of stroke, transient ischaemic } \\
\text { attack, or carotid revascularisation }\end{array}$ & Statins & \\
\hline \multicolumn{3}{|l|}{ Laboratory tests: } \\
\hline Fasting plasma glucose & $\dagger$ & $\begin{array}{l}\text { Every } 6 \text { months for the first } 3 \text {, every } 12 \\
\text { months thereafter }\end{array}$ \\
\hline Oral glucose tolerance test & $\dagger$ & Every 12 months \\
\hline Glycated haemoglobin $\left(\mathrm{HbA}_{1 \mathrm{C}}\right)$ & $\dagger$ & Baseline only \\
\hline Low and high density lipoprotein cholesterol & Statins & Baseline and 3 years \\
\hline Triglycerides & Statins & Every 12 months \\
\hline \multicolumn{3}{|l|}{ Drugs: } \\
\hline Statins, $\beta$ blockers, calcium channel blockers, and diuretics & & Every 6 months \\
\hline
\end{tabular}

*Drug thought to be indicated by or associated with corresponding variable.

†Variables not directly related to treatment initiation but highly associated with new onset diabetes. 
Table 2| Baseline characteristics of treatment naïve patients, by subsequent initiation. Values are median (25th, 75 th centile), unless stated otherwise

\begin{tabular}{|c|c|c|c|c|c|c|c|c|}
\hline \multirow[b]{2}{*}{ Characteristics } & \multicolumn{2}{|c|}{$\beta$ blocker $(n=5640)$} & \multicolumn{2}{|c|}{ Diuretic $(n=6346)$} & \multicolumn{2}{|c|}{ Statin $(n=6146)$} & \multicolumn{2}{|c|}{ Calcium channel blocker $(n=6294)$} \\
\hline & Yes $(n=915)$ & No $(n=4725)$ & Yes $(n=1316)$ & No $(n=5030)$ & Yes $(n=1353)$ & No $(n=4793)$ & Yes $(n=1171)$ & No $(n=5123)$ \\
\hline Age (years) & $64(58,69)$ & $63(58,68)$ & $64(58,69)$ & $62(58,68)$ & $63(58,68)$ & $63(58,68)$ & $64(59,69)$ & $62(58,68)$ \\
\hline Female (\%) & 50.6 & 52.6 & 50.0 & 45.6 & 51.0 & 56.0 & 51.2 & 51.9 \\
\hline Black (\%) & 3.1 & 2.8 & 2.8 & 1.6 & 2.1 & 2.8 & 2.6 & 2.2 \\
\hline Hypertension (\%) & 80.0 & 69.1 & 85.3 & 65.6 & 76.6 & 83.5 & 86.8 & 65.3 \\
\hline Congestive heart failure (\%) & 3.3 & 2.0 & 3.1 & 1.6 & 2.8 & 3.6 & 3.9 & 3.8 \\
\hline Total cholesterol (mmol/L) & $5.4(4.7,6.2)$ & $5.5(4.8,6.2)$ & $5.4(4.7,6.2)$ & $5.4(4.7,6.1)$ & $6.0(5.3,6.7)$ & $5.5(4.8,6.2)$ & $5.5(4.7,6.2)$ & $5.4(4.7,6.2)$ \\
\hline History of CABG (\%) & 4.5 & 2.8 & 5.0 & 6.4 & 3.0 & 1.4 & 6.0 & 5.3 \\
\hline History of angina (\%) & 15.3 & 8.8 & 17.4 & 16.8 & 13.0 & 10.6 & 17.1 & 14.8 \\
\hline Fasting glucose (mmol/L) & $6.0(5.7,6.4)$ & $6.1(5.7,6.4)$ & $6.0(5.7,6.4)$ & $6.1(5.7,6.4)$ & $6.0(5.7,6.4)$ & $6.1(5.7,6.4)$ & $6.1(5.7,6.4)$ & $6.1(5.7,6.4)$ \\
\hline $\mathrm{HbA}_{1 \mathrm{c}}(\%)$ & $5.8(5.5,6.1)$ & $5.8(5.5,6.1)$ & $5.8(5.5,6.1)$ & $5.8(5.5,6.1)$ & $5.8(5.5,6.1)$ & $5.8(5.5,6.1)$ & $5.8(5.6,6.1)$ & $5.8(5.5,6.1)$ \\
\hline
\end{tabular}


Table 3| Effect of time dependent drugs on progression to diabetes

\begin{tabular}{|c|c|c|c|c|}
\hline Drugs & $\begin{array}{l}\text { Unadjusted hazard ratio (95\% } \\
\qquad \mathrm{Cl})\end{array}$ & $\begin{array}{l}\text { Baseline adjusted }{ }^{*} \text { hazard ratio } \\
\qquad(95 \% \mathrm{Cl})\end{array}$ & $\begin{array}{l}\text { MSM adjusted } † \text { hazard ratio } \\
(95 \% \mathrm{Cl})\end{array}$ & $\begin{array}{c}\text { Absolute excess risk† }(95 \% \mathrm{Cl}) \\
\text { at } 5 \text { years }(\%)\end{array}$ \\
\hline$\beta$ blocker & 1.25 (1.07 to 1.46$)$ & 1.23 (1.05 to 1.44$)$ & $1.10(0.92$ to 1.31$)$ & $2.6(-2.3$ to 8.0$)$ \\
\hline Diuretics & 1.36 (1.20 to 1.55$)$ & $1.36(1.19$ to 1.55$)$ & $1.23(1.06$ to 1.44$)$ & $5.9(1.5$ to 10.7$)$ \\
\hline Statins & $1.30(1.14$ to 1.48$)$ & 1.30 (1.13 to 1.49$)$ & $1.32(1.14$ to 1.48$)$ & $8.1(3.5$ to 13.0$)$ \\
\hline Calcium channel blocker & $1.01(0.87$ to 1.18$)$ & $0.98(0.84$ to 1.14$)$ & $0.95(0.79$ to 1.13$)$ & $-1.5(-5.8$ to 3.4$)$ \\
\hline
\end{tabular}

MSM=marginal structural model.

*Standard Cox proportional hazard model with regression adjustment for baseline variables, and treatment included as a time dependent covariate. †MSM with regression adjustment for baseline variables and inverse probability of treatment weighting for time dependent confounders; truncation of extreme weights applied at 0.25 th centile and 99.75 th centile. 


\section{Figure}

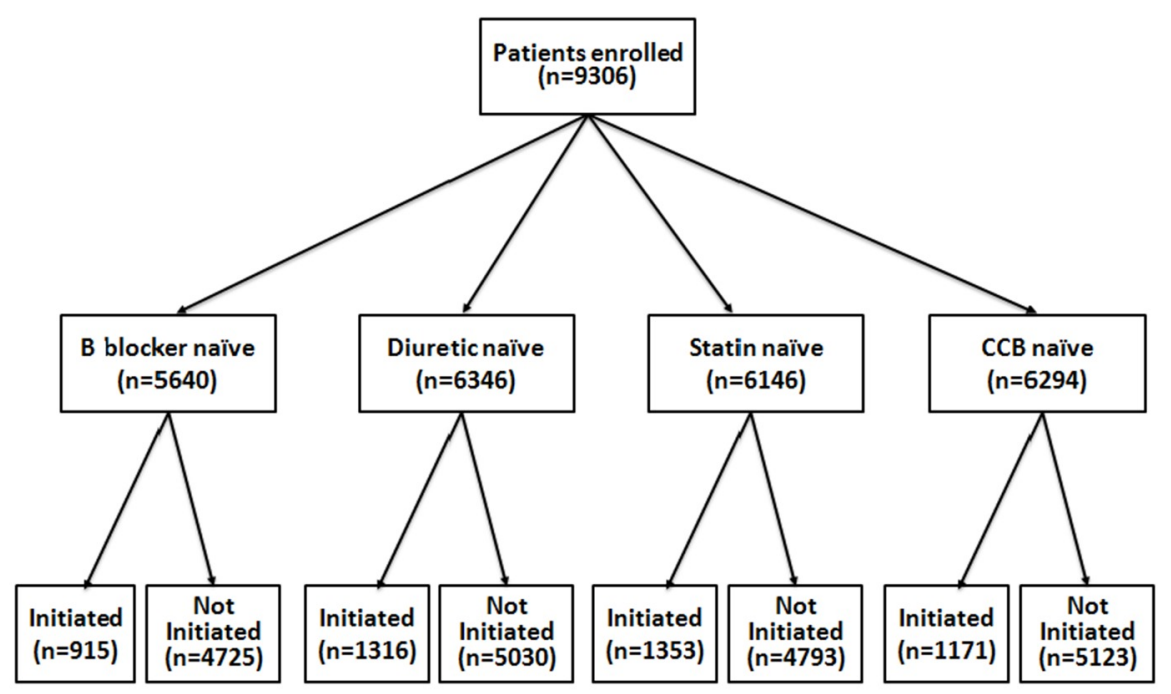

Patients enrolled in NAVIGATOR trial and their use of drugs of interest at baseline. CCB=calcium channel blocker. Cohorts are not mutually exclusive but may receive other drugs 